\title{
GRECIAN RIDDLE-JOKES: \\ FORMALISTIC AND FUNCTIONAL \\ FEATURES OF A NEW MINOR FORM
}

\section{Evangelos Gr. Avdikos}

It is a common knowledge that different kinds of folklore interact and develop their energy within a small group (Dundes 1965: 1) which enables its participants establish interpersonal relationships. Consequently, all members of the interactive narrative companionship could work as active bearers of folklore transmitted to other geographical areas, or different sex, race, age groups (Thomas 1989: 95-99, Shils 1981: 12-13). For spreading, the narrative and Minor Forms (Chatzitaki-Kapsomenou 1990: 1) used to make use of face to face communication and people's movement and travelling from one region to another.

In the last decade, however, things have changed considerably. The form of communication in the pre-WW 2 period has gradually died out. Oral interaction and transmission of folklore imposed its own effectiveness on people due to the given social conditions.

The reversal of all those parametres in the post-WW 2 period disrupted the social context and caused the emergence of other forms of communication. Technological communication (Bausinger 1990) changed ways of thinking and behaviour and established new vehicles for social contact. Newspapers, magazines as well as radio and TV channels (see Dégh 1994) entered into communication and have often substituted oral transmission in the area of cultural production.

That has been made clear regarding the Minor Forms and the way of being used by the journalists. Those journalists ${ }^{1}$ in particular who are concerned with writing comments columns are also interested in looking either for proverbs, riddles or jokes. All the narrative material promotes their effort to formulate their thoughts and make their caustic comments in an implying and succinct way.

Thus, in the course of transmission this new function and application cultivated prerequisites of different quality for the Minor 
Forms. The most subversive is the fact that the previous close link between active bearer and audience was broken as media had been interposed by transforming the communication conditions. Pertinent to that is the Lixfeld's observation that "jokes can spread indirectly through the mass media, through newspapers, television, radio, or popular anthologies. In such cases the mass media stand between the communicator and the recipients. That thwarts the firsthand contact and causes the communication to be one-sided / -/ Oral transmission takes place mostly in a small circle of participants, which promotes a mutual exchange process" (Lixfeld 1986: 239).

These aspects could also be extended to the Minor Forms. Thus, we will specify our arguments on riddles. We will focus on the role and significance attributed to such folklore genres by technological communication. ${ }^{2}$

In Greece, at the beginning of the 1990s the circulation of riddles flourished among teenagers, mostly in schools. Riddles could be heard everywhere. Its oral forms appeared in newspapers (Barrick 1974: 253-257), particularly in commentary columns.

Below I intend to concentrate on shedding light on three following points:

\section{THE ROLE OF NEWSPAPERS IN THE SPREAD AND REVIVAL OF THIS FOLKLORIC GENRE.}

It is a well known fact that mass media occupies a predominant position in disseminating information, having the exclusive privilege to reach the majority of population. The comments columns have made the role of newspapers even more effective because of brevity, the power of arbitrariness and succinctness.

So, the comments columns have taken over some levels of interpersonal contact in such a performance of folklore genres. That occurs in one of such newpaper comments columns, the so-called "Mavri Tripa" (Black Hole) column. Themos Anastasiades, the columnist, explained me his experience over a telephone interview. "I received calls from kids in "Eleftherotypia", my editorial office. They asked for mister Themos - me - and then said a riddle breaking out in 
laughter. I can not imagine something more authentic in terms of genuine humour and communication. Another observation: with riddles the communication with our readers was intensive but never too regular. People faxed us riddles from across the world: America, England, etc. Also, we received them by Internet."

The columnist transparently outlines the newly established reality in place of learning and performing Minor Forms. Journalist functions here as a reference point for picking up narrative material. At the same time it provides feedback for the newspaper readers. In the past oral transmission limited the number of riddletellers to a specific group consisting of schoolmates, neighbours, relatives, friends and colleagues at work. In the new riddle-telling situation, performance becomes more dynamic in order to reach the largest possible number of recipients.

On the other hand, recipients are turned into informers who introduce new riddles to the columnist. The feedback relation between riddle-posers and answerers, the main trait of riddling situation keeps existing through new forms and frameworks.

Apart from what is pre-eminent in the new environment of riddling and its circulation is the establishment of a new framework for disseminating riddles. Newspapers function as a reference point both for collecting material and passing it on to a huge number of recipients who find the riddles by reading a specific newspaper.

In addition, a circle of interaction could be formed, within which newspapers have replaced the visible and well-surrounded premises of houses, shops, the whole neighbourhood. ${ }^{3}$ In the past the riddling group covered a certain territory, one of the main preconditions for the riddle game and for establishing communication. The newly established riddling situation differentiated those conditions and made the context of interaction more arbitrary.

Today, newspapers function as the meeting territory for riddle-tellers. More importantly - the meeting place is no longer significant. Instead, the material dimension loses its tangible attributes and is supplemented by the newpaper pages. The specific limited place of the comments column on a page constitutes the meeting point, i.e. the territory for the members of the group who are interested in 
learning new riddles to enrich their own repertoire. Now, the pervasive feature of the group is not the sense of belonging to a specific territory but the decision to be one of the newspapers' readers. Anybody who buys the newspaper, automatically joins the circle of the recipients. They use newspaper as an arbitrary territory which provides them the satisfaction of solving riddles; that, in turn ,recounts in their companionship.

So mass media ${ }^{4}$ has acquired a crucial role in the spread and revival of the Minor Forms. They preserve riddles and feed material to their readers. Also they contribute to a quick migration of motives and narrative forms from one geographical area to another, even abroad. In that sense technological communication vindicates the transmission of cultural forms. Internet and newspapers extend the territory of performance by giving it a worldwide dimension. Such narrative forms can migrate immediately and circulate among different geographical areas abolishing frontiers and distances. Therefore, this process is considered a determining factor in an effort to enrich and reinforce riddling situations. Generally speaking, we can argue that the whole process functions as a vital factor for revitalising Minor Forms.

\section{THE SOCIAL CONTEXT OF A RIDDLING SITUATION.}

Another important point in our approach is the context where the riddling situation is developed. Remarkably, the majority of those involved in such a riddling activity are the youngsters. ${ }^{5}$ "Riddles were being told by the school-kids", Themos Anastasiades observes. Schoolchildren worked as both bearers and performers of riddles. Certainly, it is not a mere coincidence.

The fact owes to the expressive peculiarities of those verbal forms which render the playing with words, phrases, social facts and concepts possible. Riddles based on metaphors (Köngäs Maranda 1971: 193-194) and surrealistic images are acceptable for adolescent character, providing tools for disputing ideas, social practices and making fun of all these conditions. They are very similar to how youth in the age of puberty face the elderly. They regard them as representatives of another world accused of hypocrisy, compromise, conformism, conservatism. They reject the whole system of think- 
ing and behaviour characteristic to the other side, at the same time not rebelling against them. They do not become active by seeking an alternative world, but are often enraged by social manifestations, and feel confused.

However, the youngsters do not move on by struggling with various challenges. They divert their subvertive stance into verbal forms of dispute. Riddles offer appropriate linguistic means for transforming the adolescent necessity to dispute into a linguistic play with words which results in a purifying process through parody (Freud 1905: 200-201) and laughter. The context above has even excluded the youngsters' answers about the function of riddles. The first response was: "We were fed up with swear-riddles and we wanted to get even with the older generations who accuse us of using bad words."

The second answer: "These riddle-jokes are a means for parodying social situations which sometimes may bother us and in other cases can make us laugh" (Yoyakas \& Elefteriadou 1996: 41).

\section{THE FORMALISTIC STRUCTURE AND FUNCTION OF RIDDLES}

We have collected some of the riddles found in newpapers. Also, I wrote down riddles I heard at the working places and from circles of people:

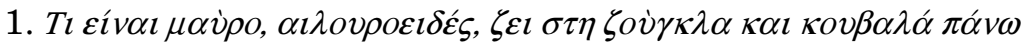

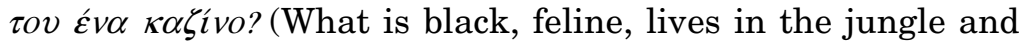
carries a casino on it?) - O Пর́ $\rho v \eta \theta \alpha \varsigma$ (Parnithas).

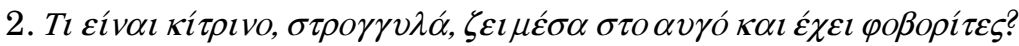
(What is yellow, round, lives in the egg and has whiskers?) - $O$

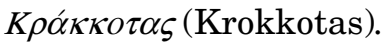

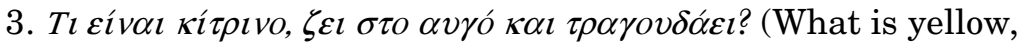

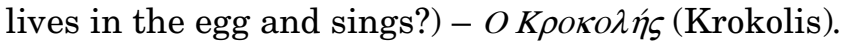

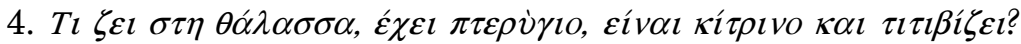

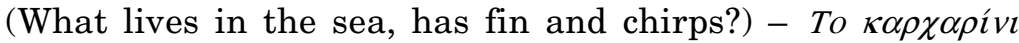
(Karharini). 


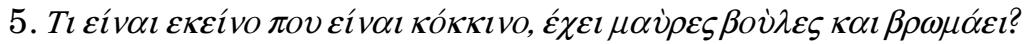
(What is red, has black spots and stinks?) - H $\mu \alpha \sigma \chi \alpha \lambda i \tau \sigma \alpha$ (Mashalitsa).

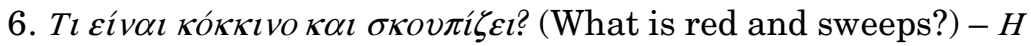

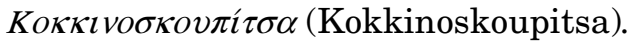

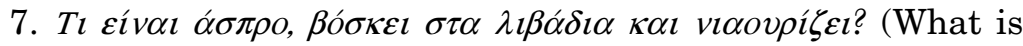
white, browses in the meadows and mews?) - To $\pi \rho o ́ \gamma \alpha \tau o$ (Progato).

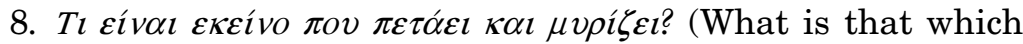
flies and smells?) $-H \mu \pi \varepsilon \kappa \alpha ́ \lambda \tau \sigma \alpha$ (Bekaltsa).

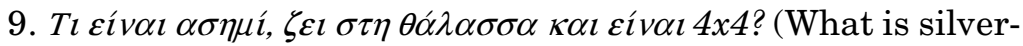
coloured, lives in the sea and is $4 \mathrm{x} 4$ ?) $-H \tau \zeta \imath$ I 0 i $\rho \alpha$ (Jeepoura).

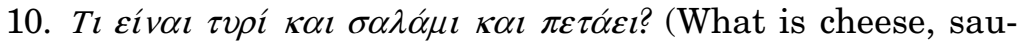
sage, and flies?) - $O \alpha \eta \tau o \sigma \tau$ (Aetoast).

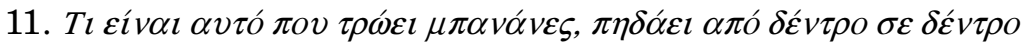
$\kappa \alpha \imath \tau \rho \alpha \gamma o v \delta \alpha \dot{\varepsilon} \varepsilon$ ? (What is that which eats bananas, jumps from

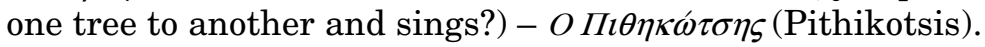

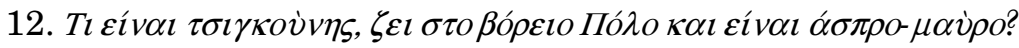
(What is that which is niggard, lives at the North Pole and is

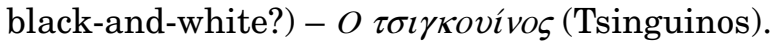

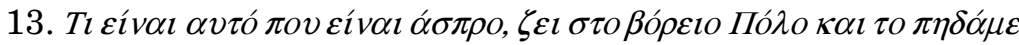

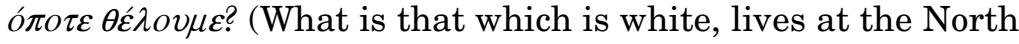
Pole and we lay it whenever we want?) - Н $\alpha \rho к о \dot{\delta} \delta \alpha$ (Arkouda, 'bear').

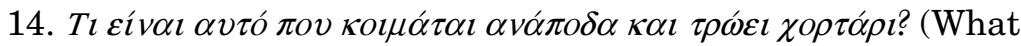

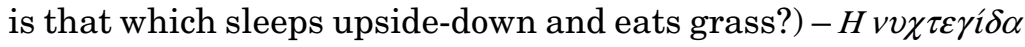
(Nichtegida).

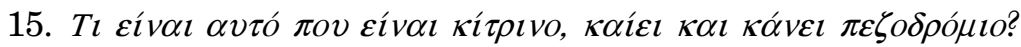
(What is yellow, hot and cruises?) - Пov $\sigma \tau \alpha \dot{\rho} \delta \alpha$ (Poustarda).

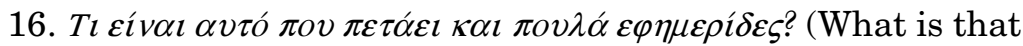
which flies and sells newpapers?) - To $\pi \varepsilon \rho \imath \tau \varepsilon \varepsilon \rho$ (Peripteri).

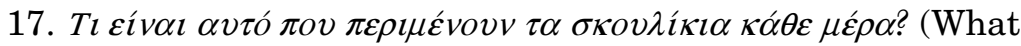

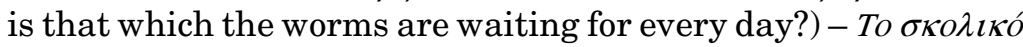
(Skoliko). 
As to the previous examples, the riddling is focused on the answer not just as a solution through mental combinations of common elements between incompatible riddle images and response (Dundes \& Georges 1975: 95), but as an ambiguous word which provokes parody and makes the participants laugh. This is why the above folklore forms are called riddle-jokes. They are not traditional riddles where the answerer seeks for the solution and is satisfied with his achievement.

In all these folkloric forms are based on parody and laughter. In this sense all the above examples would elude the well-known category of riddles. They integrate into the performance functions of jokes of which parody and comedy are most common. "The punch line is the obvious keystone of the joke/_/ as it determines whether the text qualifies as a joke. The quality depends on the success of the collapse of expectations. An analysis based on the punch line must therefore result in substantial insights into the inner structure, into the inner mechanism of jokes, even though the emotional reaction of human laughter will not be explained" (Lixfeld 1986: 235).

The response is analogous to the punch line in its functioning as the parody and laughter therapy on the participants. Both of these above contribute to cultivating an atmosphere of hilarity which differentiate these riddles from the acceptable riddling forms. All those examples consist of components and are conditioned by functions which prompt us to classify them into a mediary subcategory combining elements of both riddle and joke.

Introducing the analysis we should underline that the linguistic form of such folkloric forms is similar to a subgroup of riddles, the "more A than A" subgroup. According to Elli Köngäs Maranda its syntax is formed as follows: "What is + adjective as a basis of comparison (in the passive case) + comparative form of the same or synonymous adjective" (Köngäs Maranda 1971: 220).

In the case of riddle-joke, there is a similarity with the opening of "what + adjective". However, riddle-joke is differentiated from the rest by the structure of the narrative form. 
This folkloric genre is constituted by a descriptive element consisting of a topic, which is implied, and a comment (Caro 1986: 177). The former is rendered by the introductory questioning phrase "What is". The rest of the phrase is a comment including one or two adjectives as well as one or two sentences with non-auxiliary verbs. So we can have the simple structure and its own variations.

What is (or what is that) + one adjective + one sentence (non-auxiliary verb)

Example 6 belongs to this basic form of structure. Variants of this is the riddle-joke with two adjectives, and one sentence (example 1). Another variant consists of one adjective and two sentences (examples 2, 3, 5, 7). In addition, there are forms with nouns instead of adjectives $(9,10,12)$. Another variation consists of sentences only.

Anyway, all these constituents are parts of the riddle-joke image, which is the vehicle in the riddling situation. However, these examples develop their distinct trait distinguishing them from the riddles. Example 1 is more similar to the traditional riddles of that form. The comment consists of two parts. The first misleads the hearer directing him to a specific place in order to find the answer (see Hamnett 1967: 379-392). The first part of the comment (black, feline, lives in the jungle) refers the realm of animals but the second part (carries a casino on it) reverses the quest. This comment adds a surrealistic dimension to the riddle image, as it is impossible for an animal to carry a casino on it. Surrealism is inherent to these folklore forms (Meraklis 1992: 30).

The answer to the first riddle-joke is Parnithas. The second part of the comment creates the surrealistic riddle image, and at the same time it orients the participants towards an answer, not identified in the information given in the first part of the comment. Parnithas is a Greek mountain just at the outskirts of Athens. It is an attractive place for the local population because of its ski facilities and the casino. Moreover, the word Parnithas plays with another answer from the animal realm - the panther. This could be inferred from the first part of the element. Through the last sentence the answerer takes a jump from the animals to the natural enviroment. The mediary phrase (lives in the jungle) operates as the combining 
link establishing a metaphor between the first implied answer (panther, which lives in the jungle) and the final answer (Parnithas) reminding the participants of the metaphorical jungle of Athens, of which Parnithas is a symbolic and succinct word.

Besides, there is a pun with words 'panther' (Panthiras in Greek) and 'Parnithas'. Both of the words are combined through the anagram. By re-arranging the letters ' $n$ ', ' $h$ ' and 'r', by moving them to other positions we can make a linguistic play which is the essential goal of these riddle-jokes. This play presupposes that all those concerned (posers and answerers) belong to the same cultural system. ${ }^{6}$ It entails that all the members of riddling-joking situation are familiar with the meaning of the words, literal and symbolic. Outsiders can not enjoy the linguistic play.

This aspect becomes more obvious in the examples 2 and 3 . The linguistic traits become more important in the function of riddlejokes. Both of the above examples have a common first part of the comment (What is yellow, lives in the egg). Example 2 adds the adjective 'round'. The first half of the comment creates a strict image with a clear answer - it describes the yolk of an egg. The linguistic play starts in the second half of the comment. Example 2 includes additional information 'has whiskers', while example 3 is supplemented by the phrase 'sings'. This combination creates a paradoxic situation. The first half is organised around a conditional image, which becomes a paradox when a new characteristic is added, not compatible with the first one. For participants it is bizarre and extraordinary to accept this non natural dimension. Yolk cannot have whiskers or sing. This could be acceptable only as a surrealistic image where the solution depends on the linguistic play of the combination of a syllable cut off from both of these two implied answers. So in example 2, the implied answer to the first half is krokos (yolk), whereas the answer for the second half is Kokkotas, the name of a popular Greek singer. The answer 'Krokkotas' is an artificial appending of two halves.

Krok- $($ kro-kos $)+-$ kkotas $($ Ko-kkotas $)=$ Krokkotas

So, as a result of an artificial appending we will have the answer 'Krokkotas'. The final solution does not make sense. The same happens in example 3. 
Kro- $($ kro-kos $)+-$ kolis $($ Kor-kolis $)=$ Krokolis

The first half of the answer is cut off from the the first half of the comment, and the second half from the respective element. Apart from the technique applied for the synthesis of answer, the essence of all these riddle-jokes is the linguistic play. This takes place as an end in itself and it functions as a riddle within the riddle-joke. The answer without making sense creates parody ${ }^{7}$ for the new word and make its hearers break out in laughter because of the implied but incomplete images, which are also overlapping. In both riddlejokes (examples 2 and 3 ) the second part is extracted from the surname of two famous Greek singers: Kokkotas and Korkolis). In this case, we can speak of a parody being directed towards two public persons, jokes based on the names of celebrities are relatively popular in this particular folkloric genre (see also example 11)

However, the rest of the riddle-joke examples are more intensively based on the linguistic play of the answer. So in example 4 the two implied answers are: Karcharias ('shark') + kanarini ('canary'). By cutting them in pieces we will have the answer:

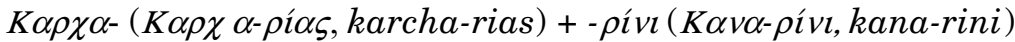
$=\kappa \alpha \rho \chi \alpha \rho \mathrm{i} v \iota$ (karcharini).

In this case, the answer does not make sense except for the linguistic play. So, we argue that the linguistic play is a purpose in itself. The participants are not interested in establishing a riddle according to the traditional forms. Their intention aims at the parody of the riddling process itself.

This observation is further emphasised in the other riddle-jokes.

5. $M \alpha \sigma \chi \alpha-(M \alpha \sigma \chi \alpha \dot{\alpha}-\lambda \eta$, mascha-li, 'armpit') $+-\lambda i \tau \sigma \alpha(\pi \alpha \sigma \chi \alpha-$ $\lambda i \tau \sigma \alpha$, pascha-litsa, 'cowslip') $=M \alpha \sigma \chi \alpha \lambda i \tau \sigma \alpha$ (maschalitsa).

The difference between this and the other examples is that its answer has been made up by reversing the line of the halves. So the half from the second comment is put at the beginning of the answer, while the first one is placed at the end. The first part of the comment refers to the cowslip but the second one turns our attention towards something else. The final answer is not rational. It is 
surrealistic itself and at the same time poses a question similar to a riddle.

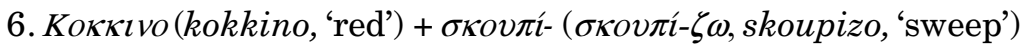

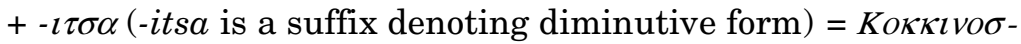

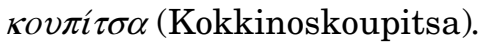

In the previous riddle-joke, the answer is made up of the whole first, and the first part from the second one, in which the diminutive suffix -itsa is added. So the result is a linguistic parody of Little Red Riding Hood, the famous heroine of a folktale. Probably, it is a subversive stance vis-à-vis leading folkloric figures dominant in the participants' childhood entertainment by asking a question about what determined their own entertainment patterns.

With the following example we will revert to the more linguistic version.

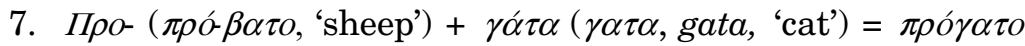
(progato).

The final answer is composed of a part of the first half, while the second one is rendered in its full form. Everybody can see the linguistic form and function of the answer 'progato'. It has no sense ${ }^{8}$ in terms of the vocabulary and the subjects. It is just a linguistic and surrealistic synthesis. It exists outside social contexts and established grammar rules. It is a product of a riddle-joke. However, it acquires its own function which is juxtaposed to the riddle-joke. This situation allows it to be turned into a riddle and work as a surrealistic comment on the production and function of riddles.

8. $M \pi \varepsilon \kappa \alpha-(M \pi \varepsilon \kappa \alpha-\tau \sigma \alpha$, bekatsa, 'woodcock') $+-\lambda \tau \sigma \alpha(\kappa \alpha \lambda-\tau \sigma \alpha$, kaltsa, 'sock') $=\mu \pi \varepsilon \kappa \alpha ́ \lambda \tau \sigma \alpha$ (bekaltsa).

The answer 'woodcock' to the first part of the comment ('What flies') is arbitrary. The importance of the linguistic play is expressed in the second part of the comment referring to one of the familiar subjects to children like socks. So in this case we can spot a selfsarcastic trend in terms of their habit and behaviour. Dirty socks are thrown away after having been taken off, which reminds the flying of birds. In this way, the choice of woodcock is justified. It 
has no sense that is not directly correlated to what is described by the poser. The first part of the comment is not read literally.

9. $T \zeta \imath \pi$ ('Jeep') + -ov่ $\rho \alpha(\tau \sigma \imath \pi$-ov่ $\rho \alpha$, tsipoura, 'snapper') $=T \zeta \imath \pi \circ \dot{v} \rho \alpha$ (Jeepoura).

It is a fascinating conception in terms of exploiting social conditions and making parody of social practices through the final answer. It was a popular habit of successful people to drive jeep $4 \times 4$. They often managed to get a car licence that was given only to farmers. This riddle-joke creates an excellent sound and visual result. The word $T \zeta \imath \pi o v \rho \alpha$ 'Jeepoura' incorporates sounds, pictures and social stances in an incompatible way. However, this combination provides expressive tools for outlining the desired meaning.

10. $A \eta-(\alpha \eta-\tau o ́ s$, aetos, 'eagle') $+\tau o \sigma \tau($ tost, 'toast') $=A \eta \tau o ́ \sigma \tau($ Aetost $)$.

Another example of the riddle-joking situation where the play itself is the aim, without taking into consideration whether the answers to the comments respond to what is described or not. Moreover, in example 10 we can observe the reversal of the synthesis of the final answer. It begins with the second comment. The answer $\alpha \eta \tau \alpha$ c 'eagle' does not exactly correspond to the comment as it asks what 'flies' and that provides a general feature common to all birds. In this way, the poser braces the surrealistic thinking. At the same time, he lightens the sentence and makes it more flexible and functional as a part of a riddle-joke.

The final answer 'aetost' is a word-caricature. It exceeds the common way of thinking and making words. It is the crucial point which allows scholars to get to the bottom of its formalistic and functional traits.

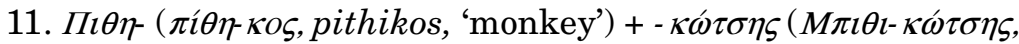
Bithikotsis $)=\Pi \imath \theta \eta \kappa \omega ́ \tau \sigma \eta \varsigma($ Bithikotsis $)$.

This riddle-combination belongs to the same subgroup with examples 2 and 3. They combine a part of the answer $\pi i \theta \eta$ - $\kappa o \varsigma$ 'monkey' of the first half of the comment (What is that which eats bananas, jumps from one tree to another) with the second half of the answer to the second part of the comment. The answer refers to a Greek singer, whose surname is $\Pi \imath \theta \eta \kappa \omega \tau \sigma \eta \varsigma$ Bithikotsis. The final answer 
sounds like a play with the singer's surname. Probably, the poser wanted to make fun of the singer's fierce look. In combination with his frizzy hair he really leaves an impression which justifies the linguistic play.

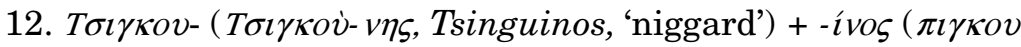

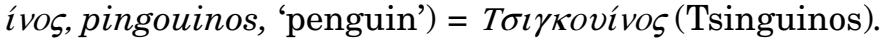

The difference between the previous riddle-joke, and the others is that the first half of the final answer is extracted from the first

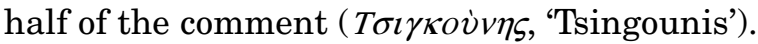

The poser comments on a phenomenon of social behaviour which isolates niggards from other people. This observation is a given fact that allows the poser to carry out his transgression in terms of how he brings both $\tau \sigma \iota \gamma \kappa o v i v$ (tsingounis, 'niggard') and $\pi \imath \gamma \kappa o v i v o \varsigma$ (pingouinos, 'pinguin') together within the North Pole background. The linguistic excess here serves as the target of social parody.

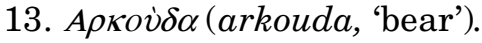

This example is very similar to a traditional riddle. The new element is associated with the second part of the comment which implies that we symbolically rape the bear. It is clear that poser activates his environmental sensitivity.

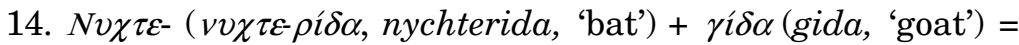

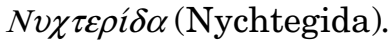

In this riddle-joke, the focus is on a linguistic exercise. The final answer is a linguistic excess which poses the riddling problem and its function within a social group. Outside the surrealistic function of the normality in the form and circulation of traditional riddles, other folkloric forms might distort what has been known from the tradition. Bat and goat are incomparable as components for a new word legalised through the function as a new riddle and within the riddle-joking situation.

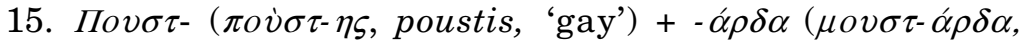
moustarda, 'mustard') $=\Pi$ lov $\sigma \tau \alpha ́ \rho \delta \alpha($ Poustarda $)$.

This riddle-joke belongs to the subgroup of riddles about sex. Poser makes up a word which gives clear sexual hints and he determines 
his own attitude. So he gets the second half of the answer to the

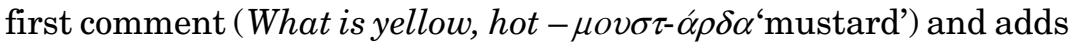
part from the answer of the second comment (cruise' - 'gay') at the beginning of the word. Moreover, he makes a reference to male homosexuals not the female ones. (The Greek word $\pi \circ \dot{v} \sigma \tau \eta \varsigma$ refers only to the male gay.) The final answer $\pi \circ v \sigma \tau \alpha \dot{\alpha} \rho \alpha \alpha$ 'Poustarda' is similar to the Greek word $\pi o v \sigma \tau \alpha \dot{\alpha} \rho \alpha$ (poustara) which is magnifying the $\pi \circ \dot{\sigma} \sigma \eta \varsigma$. In this way, the final answer takes a disdainful attitude towards gay-people. In addition, the answer $\pi \circ v \sigma \tau \alpha \dot{\alpha} \rho \delta \alpha$ works as a deforming reflection of its own components. Besides, there is another interesting point in this example which we can project even on examples 2 and. 3. The adjective 'yellow' is basic in all these riddle-jokes. If we examine this detail in the light of the context, we could argue that the yellow colour has symbolic function. Probably, it is the expression of a social atmosphere falling into decay. Possibly, the posers express their views on the current cultural and moral codes in the riddle-jokes.

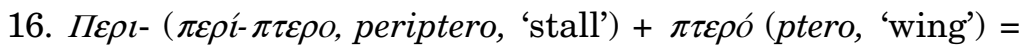
$\pi \varepsilon \rho \imath \pi \tau \varepsilon \rho \imath$ (peripteri).

In this case we have a linguistic play which makes a parody of Greek stalls. These are fraught with anything, giving the impression of getting ready to take off. It is a sound pun which is based on a vivid picture on the streets of Greek cities. We should still insist on the second part of the comment - 'sells newspapers'. It is a realistic depiction of the reality. Stallers display newspapers so that the stalls look strange, they seem to have wings, ready to fly.

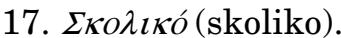

This riddle-joke has a comment consisting of only one sentence. It is organised around a combination of different words. Parody emerges from a play with a word in the riddle-joke. Skoulikia means worms. Poser plays with this word, using a sort of an anagram. The answer gives the word 'skoliko' which is the 'school bus' and the poser plays with the correct anwer scholiko in order to speak of familiar experiences from his everyday life. School buses and queuing for buses is not excactly a pleasure for the youth. 


\section{CONCLUSION}

The above analysis was based on 17 riddle-jokes only. The number is not too large, but it is, however, sufficient to clarify their forms and functions. The typology of these riddle-jokes might be the following:

a. Linguistic plays. The linguistic play is the basis of all these riddle jokes. However, we use this term to include the examples which are limited to a play with words as it happens in examples $5,6,10$, 14.

b. Reference to celebrities $(2,3,9,11)$. In this subgroup, the riddletellers intend to make fun of people both from the older generation and the youngsters. These dispute their behaviour by distorting their surname.

c. Social situations $(1,12,13,14)$. The intention of these riddlejokes is to brand negative social phenomena including environmental issues, social standards and values. All these constitute components of values and cultural system rejected by youngsters who accuse it of being hypocritical and conformist.

d. Children's experiences $(6,8,17)$. In this subgroup, they critisise facets of their own experience. They also turn into being self-sarcastic about their behaviour.

To conclude, the main characteristic which cross-cuts all the riddle-jokes is the role of technique ${ }^{9}$ over content. The final answer comes from the use of patching. It is exactly the wording patch which is the essence of riddle-jokes. In a different patch the final answer will be different or make sense in a surrealistic way only. The role of mass media (newspapers in particular) plays an important role in the spreading and revival of riddle-jokes. From the social context of a riddling situation we can conclude that the majority of those involved in such a riddling activity are the youngsters. Riddles offer appropriate linguistic means for transforming the adolescent necessity to dispute into a linguistic play with words which results in a purifying process through parody and laughter. These riddle-jokes are a means for parodying social situations and are constituted by a descriptive element consisting of a topic, which 
is implied, and a comment. The former is rendered by the introductory questioning phrase "What is". The rest of the phrase is a comment including one or two adjectives as well as one or two sentences with non-auxiliary verbs. (What is (or what is that) + one adjective + one sentence (non-auxiliary verb) or one adjective and two sentences or forms with nouns instead of adjectives). Typologically, all the riddle-jokes can be divided in 4 groups: linguistic plays, references to celebrities, parodies of social situation, children's experiences.

\section{Comments}

${ }^{1}$ Here we should mention the use of proverbs in radio programmes intended to checking the reactions of audience.

Less than a year ago, on May 6, 1955, the Finnish Broadcasting Company broadcast a radio programme consisting of three miniature radio plays, each of which broke off suddenly at a dramatic moment. Listeners were asked: What would you have said in this situation? / - / Listeners were not explicitly encouraged to produce a response to what they heard. Nevertheless, at the beginning of the programme a situation was offered, as a kind of model, the response to which was a juicy proverb. And so, among around 4000 letters that arrived the following week, in addition to individual mediations and quotations, there were some 3000 genuine proverbs (Kuusi 1994: 105).

2 "Lately, however, scholars studying proverbs have became aware of the use and function of traditional proverbs in modern technological and sophisticated societies, and we now have important studies of proverbs in modern literature, in psychological testing, and in the various forms of mass media such as newpapers, magazines, and advertisements" (Mieder 1987: 118).

${ }^{3}$ Sometimes, listeners and viewers can take the position of the audience in a folklore performance (see Avdikos 1994: 177).

${ }^{4}$ Compare this view in the light of bibliography from other folklore genres (Narvaez \& Laba 1986, Kapferer 1990: 52-58).

5 "Along the way to the adult settings, the child is a member of several folk groups, face-to-face human groups wherein people use 
stylised communication to create the sense of a shared, meaningful world / _/ A child's first experience with a folk culture of peers may be with the siblings whom the child shares a system of secret languages, nicknames, stories, riddles, jokes, traditional interaction routines, pranks, taynts, teases, toys, playhouses" (Mechling 1986: 94).

${ }^{6}$ Within this context, see an approach by Radcliffe-Brown (1971: 101-116).

7 "Parody is a common antithetical device used by children in their expressive cultures. Sometimes they parody adult roles and values" (Mechling 1986: 99).

8 "Nonsense is another important device in the child's arsenal of antithetical folk routines. Nonsense figures prominently in children's humor and strikes nicely at the heart of the adult's desire for sensibleness and rationality" (Mechling 1986: 100).

9 "The character of being a joke does not reside in the thought". In this case, "we must look for it in the form, in the wording in which it is expressed" (Freud 1905: 17). Lixfeld (1986: 238) objects to this Freudian view which is regarded one-sided. He believes that joke is a combination both of technique and intent.

\section{References}

Avdikos, E. 1994. Urban Folklore Science: Utopia or Reality? Ethnologia (Greece), 3, p. 177.

Barrick, M. 1974. The Newspaper Riddle Joke. Journal of American Folklore, 87, pp. 253-257.

Bausinger, H. 1990. Folk Culture in a World of Technology. Bloomington, Indianapolis.

Caro, F. A. de 1986. Riddles and Proverbs. Folk Groups and Folklore Genres. Edited by E. Oring. Longan Utah, p. 177.

Chatzitaki-Kapsomenou, Chr. 1990. Neohellenika Laika Aenigmata. Morphologiki kai leitourgiki analysi (Folk Riddles of Modern Greece. Formalistic and Functional Greece). Thessaloniki, p. 1. 
Dundes, A. 1965. What is Folklore. The Study of Folklore. Englewood Cliffs, New Jersey, p. 1.

Dundes, A. \& Georges, R. 1975. Toward a structural Definition of the Riddle. Analytic Essays in Folklore. Edited by A. Dundes. Paris, New York, p. 95.

Dégh, L. (Ed.) 1994. American Folkore and the Mass Media. Bloomington, Indianapolis.

Freud, S. 1905. Jokes and their Relation to the Unconsious, v. viii. London, pp. 200-201.

Hamnett, I. 1967. Ambiguity, Classification and Change: the Function of Riddles. Man, 2, pp. 379-392.

Kapferer, J.-N. 1990. Rumors: Uses, Interpretations, and Images. New Brunswick, London, pp. 52-58.

Kuusi, M. 1994. On the Aptness of Proverbs. Mind and Form in Folklore. Selected Articles. Helsinki, p. 105-113.

Köngäs Maranda, E. 1971. The Logic of Riddles. Structural Analysis of Oral Tradition. Edited by P. Maranda, E. Köngäs Maranda. Philadelphia, pp. 193-194.

Lixfeld, H. 1986. Jokes and Aggression. A Decade of Theoretical Confrontation, Debate, and Reorientation (1967-1977). Edited by J. R. Dow, H. Lixfeld. Bloomington, p. 239.

Mechling, J. 1986. Children's Folklore. Folk Groups and Folk Genres. Edited by E. Oring. Logan Utah, p. 94.

Meraklis, M. G. 1992. Greek Laographia, V 3. Folk Art (Helliniki Laographia, tomos Tritos. Laiki Techni). Athens, p. 30.

Mieder, W. 1987. The Proverb in Modern Age. Old Wisdom in New Clothing. Tradition and Innovation in Folk Literature. Hanover, p. 118.

Narvaez, P. \& Laba, M. (Eds.) 1986. Media Sense: The Folklore - Popular Continuum. Ohio.

Shils, E. 1981. Tradition. London, Boston.

Radcliffe-Brown,A. 1971. Joking Relationships. Kinship. Edited by J. Goody. Penguin, pp. 101-116.

Thomas, R. 1989. Oral Tradition and Written Record in Classical Athens. Cambridge.

Yoyakas, Pr. \& Elefteriadou, E. 1996. H amphisvitisi pou vgazi yelio (The dispute which cause laughter). Newspaper Ta Nea, April 16, p. 41. 